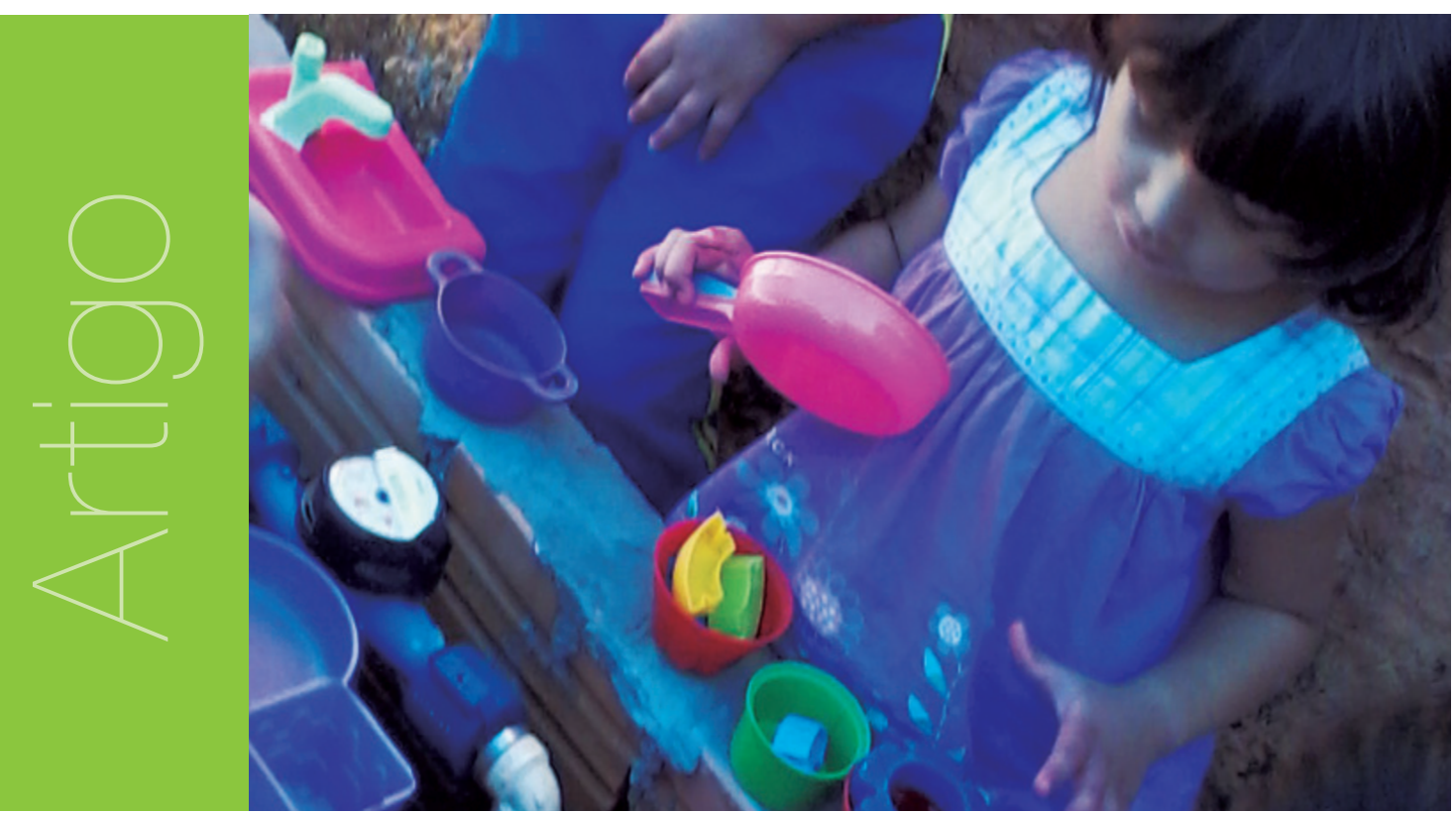

\title{
Elas estão chegando! As crianças na escola de Educação Infantil
}

\author{
Keylla da Silva1 - keylla_s@hotmail.com \\ Juliana Beatriz Machado Rodrigues² - julibmr@gmail.com
}

\section{RESUMO}

0 presente trabalho busca discutir como se dá o acolhimento das crianças na escola, desde a sua chegada à permanência. Retratando nas palavras de Gianfranco Staccioli, com o livro Diário do Acolhimento na Escola da Infância, a essência desta tarefa como "método de trabalho". Numa abordagem sensível e provocadora, mostrar a importância deste movimento na escola, de modo que se pense nas crianças mesmo quando elas não estão presentes neste espaço, reconhecendo-as como seres de escolhas e a Educação Infantil, um espaço para estar com elas e não para colocá-las, como "depósito". A aproximação com o livro tem por objetivo refletir sobre o olhar italiano, convocando a ousadia em escolas brasileiras no acolhimento de crianças, adultos e materiais, em um mesmo espaço.

\section{PALAVRAS-CHAVE}

Criança. Acolhimento. Escola da infância

\section{ABSTRACT}

This paper discusses how is the reception of children in school, from their arrival at the staying. Portraying the words of Gianfranco Staccioli with the book Reception Diary of Childhood School, the essence of this task as "working method". Into a sensitive and provocative approach,

\footnotetext{
1 Pedagoga. Professora de Educação Infantil.

2 Pedagoga, Mestre em Educação nas Ciências. Professora do departamento Ciências Humanas da Universidade Regional Integrada do Alto Uruguai e das Missões -URI campus Santo Ângelo.
} 
showing the importance of this movement in school, so that they think of the children even when they are not present in this space, recognizing it as being choices and Childhood Education, a space to be with them and not to put them as "deposit". The approximation to the book aims to reflect on the Italian look, calling boldness in Brazilian schools in childcare, adult and materials in the same space.

\section{KEYWORDS}

Child. Reception. Childhood School.

\section{Introdução}

Já é sabido que as crianças chegaram à escola infantil a partir de movimentos feministas e sindicalistas na luta pelos seus direitos e saída para o mercado de trabalho, provocando 0 Estado para garantir a oferta da Educação Infantil (BARBOSA; FOCHI, 2012), que de início este espaço era como um "depósito de crianças" vinculados "[...] à saúde em seus pressupostos higienistas; em outros, à caridade e amparo à pobreza e, em outros ainda, à educação" (HORN, 2003, p.14).

Tais práticas eram pautadas pela concepção de infância que não as percebiam como sujeitos, como criança rica, capaz, ativa, forte, sociável, competente e curiosa (FORTUNATI, 2009), 0 objetivo central deste momento era garantir um espaço que apenas abrigasse as crianças, sem qualquer laço afetivo, acolhedor e educativo, um trabalho sendo exercido e finalizado ao fim do turno, uma jornada de cada dia, uma simples repetição de fazeres na manhã seguinte: recebe-as, guarda-as, alimenta-as, limpa-as, liberta-as, volta a alimentá-las, limpa-as e, por fim, entrega-as. Dando destaque ao verbo guardá-las, usado para referir a rotina do dia a dia escolar e ao verbo libertá-las, horário e/ou momento em que as crianças possuem livre escolha em brincadeiras, brinquedos, espaço, fora do padrão adulto.

Ao longo deste percurso muito se pesquisou, publicou, debateu, a fim de que isso nos possibilitasse 0 estranhamento com estas práticas e a perceber um novo olhar para este lugar, o qual foi sendo estudado e se tornando inconcluso. Apesar de ter ganhado espaço nos vários cenários de busca, cujo objetivo é qualificar sua importância, ainda necessita, e muito, novos modos de ser pensado, idealizado e vivido.

De toda essa história vivida e brevemente situada, ficam algumas inquietações: como deveria se pensar 0 acolhimento da criança, desde sua chegada à permanência? Qual a importância deste movimento na escola da infância? Que ações levam a essa nova metodologia?

Dos arquivos interrogativos, buscamos respostas para compreender os percursos e as concepções de cada momento, e, ao respondê-las vamos tecendo novas inquietações na tentativa de ressignificar algumas práticas ou até mesmo abandoná-las. Nas pesquisas realizadas no mundo acadêmico, a concepção de infância e criança é muito rica e está distante da concepção que pode ser encontrada em muitos espaços de educação infantil.

\footnotetext{
Nos habituamos durante muito tempo pensar as crianças como seres passivos, destinatários da ação dos adultos, sem vontade, sem opinião, sem voz. A partir de uma determinada altura, o reconhecimento de que as crianças são atores sociais, ou seja, sujeitos com capacidade de ação e interpretação do que fazem, levou ao reconhecimento da necessidade, e mais que a necessidade, do direito, da criança em participar da vida coletiva. (SARMENTO, 2011).
}

Esta criança nos interpela, nos convoca a outras práticas, olhares, a outra escola, que acolha a todas, nas suas singularidades e na sua coletividade. E acolher significa pensar como uma criança entra ou sai da escola, e de que maneira pode ser a sua ambientação, suas ações cotidianas e como age nelas, suas relações e como as desenvolve, reelabora... (STACCIOLI, 2013), é pensá-la dentro deste espaço, como criança parte e por inteiro. E quando pensamos assim, não dialogamos com práticas que ainda se sustentam com a ideia de criança de outros tempos.

Acolher uma criança na pré-escola significa muito mais que deixá-la entrar no ambiente físico da escola, designar-Ihe uma turma e encontrar um lugar para ela ficar. 0 acolhimento não diz respeito apenas aos primeiros momentos da manhã ou aos primeiros dias do ano escolar. 0 acolhimento é um método de trabalho complexo, um modo de ser do adulto uma ideia chave no processo educativo. (STACCIOLI, 2013, p.25). 
Em meio a tantos pontos de interrogação nos debruçamos no livro: Diário do Acolhimento na Escola da Infância, de Gianfranco Staccioli, cuja obra apresenta de forma sensível o que significa acolher no cotidiano, na organização de espaço e do tempo para a criança movimentar e viver as primeiras experiências culturais e sociais. Uma conversa em que pudéssemos trocar olhares, palavras e leituras, [...] é um livro que conta sobre uma pedagogia feita no cotidiano, no encontro e na relação que os professores têm com as crianças construindo, verdadeiramente, uma escola da infância (com e para elas). (BARBOSA, 2013, s/p).

0 livro foi sendo construído não só de palavras, mas de sentimentos, também, pois visa uma escola da infância construída, pensada, documentada, projetada com todos os envolvidos, que movimenta, mexe e provoca outras formas de ser escola. É na voz de componentes e companheiros de jornada na luta pela infância em que se pense, viva e se respeite.

\section{Metodologia}

Nesse estudo procuramos entrelaçar práticas de viés italiano, registrado em um livro, com situações das escolas no nosso envolto, abordando possibilidades de uma nova organização: "a do sorriso e do acolhimento" (STACCIOLI, 2013), este entrelaço de ideias e encontros é registrado nas figuras abaixo: ambas aproximam teoria e pratica no cotidiano escolar.

Organizar o cotidiano das crianças da Educação Infantil pressupõe pensar que 0 estabelecimento de uma sequência básica de atividades diárias é, antes de mais nada, 0 resultado da leitura que fazemos do nosso grupo de crianças, a partir, principalmente, de suas necessidades. É importante que o educador observe o que as crianças brincam, como estas brincadeiras se desenvolvem, o que mais gostam de fazer, em que espaços preferem ficar, o que thes chama mais atenção, em que momento do dia estão mais tranquilos ou mais agitados. Este conhecimento é fundamental para que a estruturação espaço-temporal tenha significado [...]. (BARBOSA; HORN, 2001, p.67).

As evidências desse pensar pode ser constatado nas figuras registradas neste trabalho: ambas articulam 0 modo de acolher este pensamento tanto em grupo (Figura 1), onde crianças se encontram num espaço (lençol), oferecido a elas recortes e textura de modo que exploram e trocam experiências entre crianças, com adultos ou consigo (Figura 2), destacando que 0 modo de acolher é respeitar escolhas e/ou proporcionar novas, oferecendo possibilidades de socialização e encontros nos diferentes espaços da escola (Figura 3), configurando os ambientes com olhares e detalhes da infância.

[...] Como contraponto o autor propõe uma escola da infância acolhedora. Uma escola que respeite os direitos das crianças e, consequentemente, das famílias e dos professores e professoras oferecendo a todas as crianças possibilidades de viver, aprender, conviver e, ao mesmo tempo, singularizar-se. (BARBOSA, 2013, s/p).

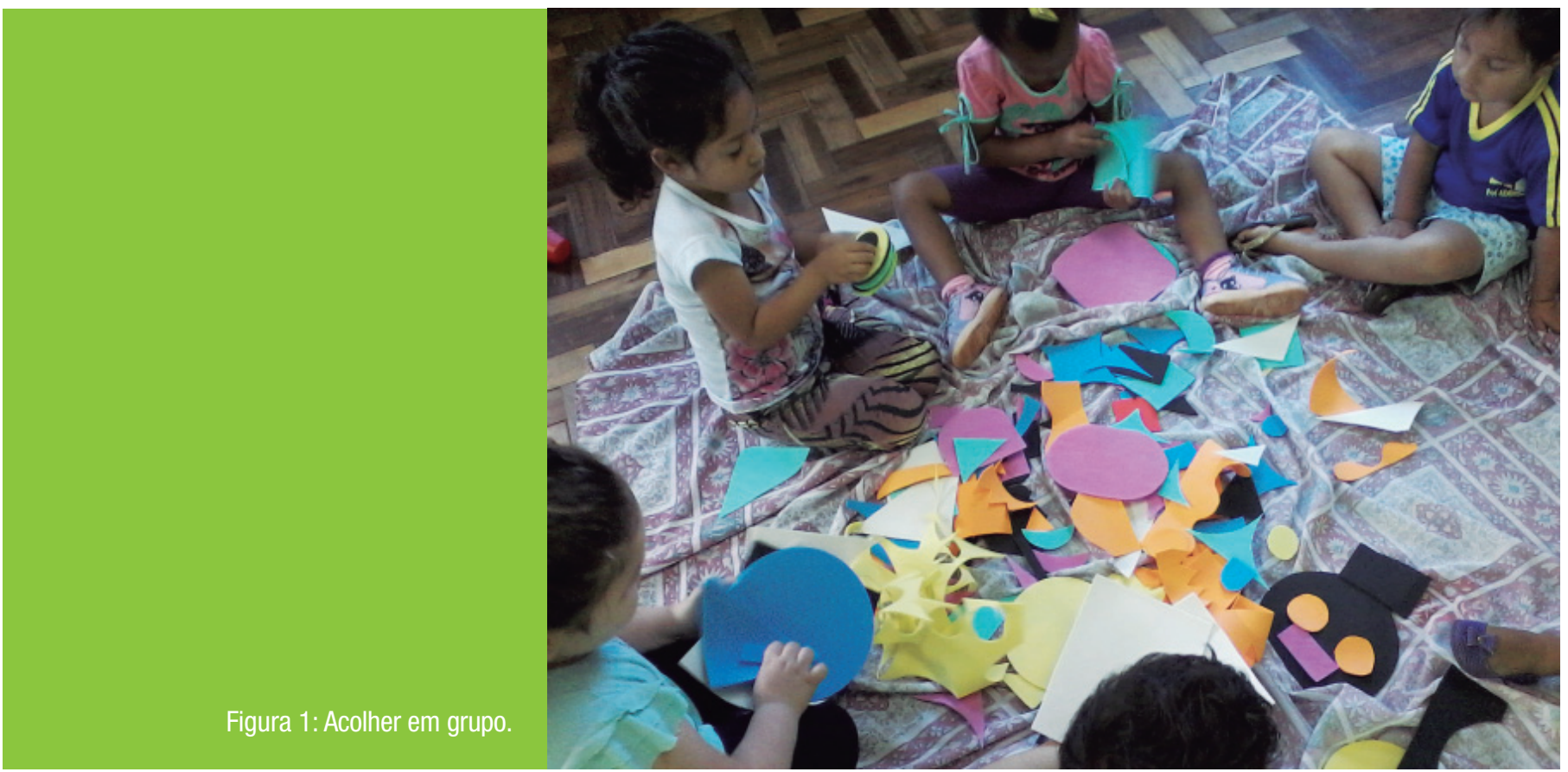



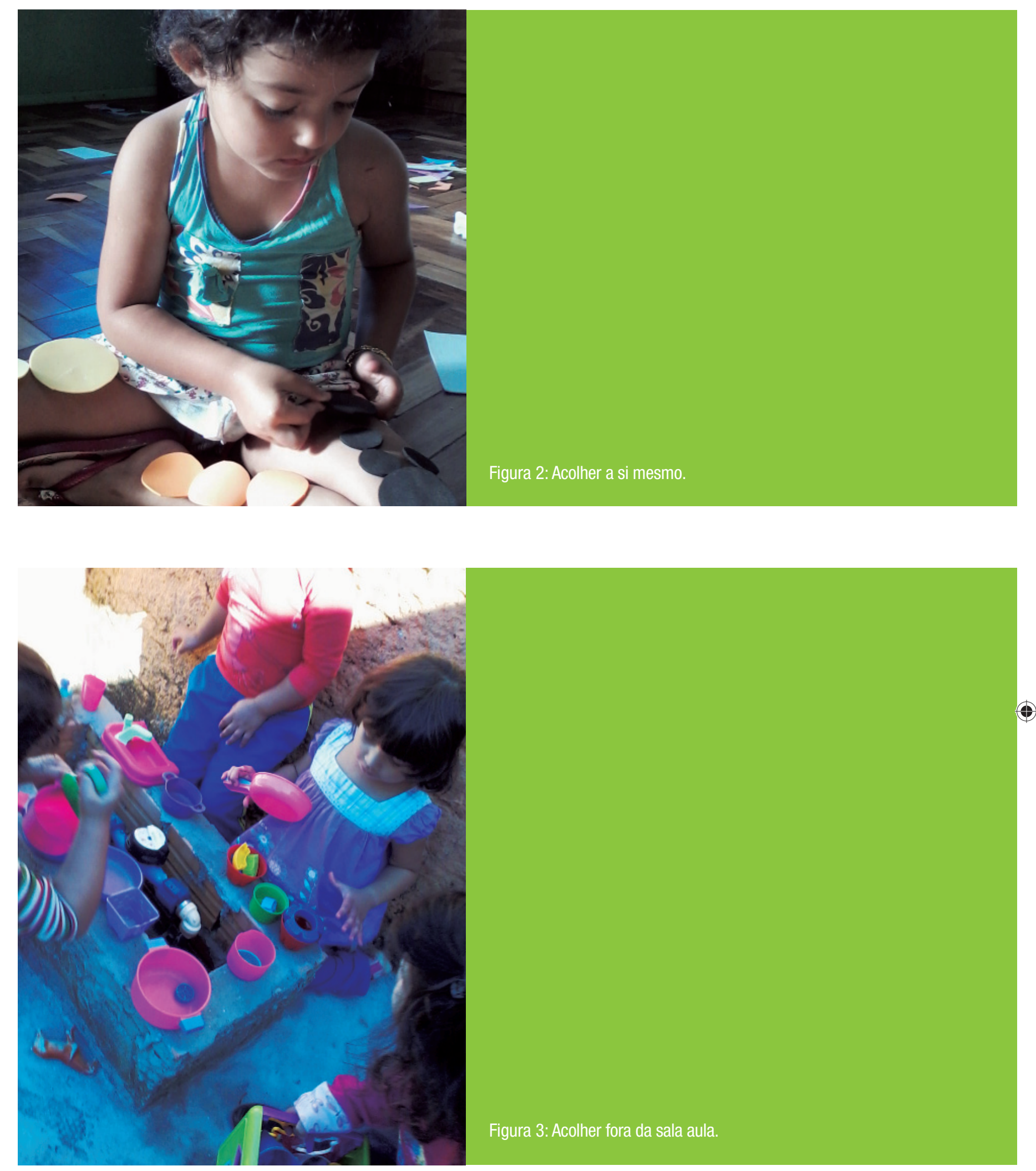

\section{Resultados e discussão}

De início, um chamamento para parar o olhar e se envolver na leitura sensibilizadora que 0 autor e seus colaboradores construíram no envolto deste livro, da capa a última palavra descrita. Integrando um universo escolar de modo que fosse possível sentir como se dá o acolhimento na escola da infância, com atrevimentos e movimentos, no dia a dia, corriqueiro de experiências únicas, presa em nosso repositório de lembranças. "As experiências são filhas do tempo e não podem ser repetidas da forma como foram realizadas [...]" (STACCIOLI, 2013, p.03). 
Mas, então, como se dá o acolhimento na escola, lugar que transpira infância? Neste recinto cheio de escritas que fomos encontrando respostas e texturas de ver esse lugar e seus cômodos com outros olhos "[...] pois sua obra traduz em palavras ternas e justas como o mundo da escola da infância pode ser para as crianças um lugar de alegria, confiança e, portanto, também de uma outra aprendizagem" (BARBOSA, 2013, s/p).

Mergulhamos mais a fundo nesse maravilhamento de palavras, onde 0 autor retrata a história, não de hoje, tempos atrás, como foi construído esse lugar, como ele foi pensado e vivido. Nas escritas ele traz três breves considerações que emergem da experiência relatada (STACCIOLI, 2013, p.03).

1. Um grupo de adultos - [...] Imaginemos hoje um conjunto de professores, com pais, funcionários e estagiários, reunindo-se alguns dias antes do início das atividades para refletir sobre como poderiam organizar um ambiente educativo adequado para as crianças da pré-escola [...].

2. Os princípios do respeito às crianças, da busca pela sua autonomia, da colaboração e da privacidade deixam de ser apenas enunciados e se concretizam como prateleiras, ganchos para pendurar objetos pessoais, papel higiênico colocado na altura certa, livros ao alcance das mãos e cantinhos gostosos [...].

3. As crianças contribuem para o seu 'bem-estar' [...] Organizar o ambiente, fazer com que as crianças participem, não é um expediente didático, é um estilo de comportamento. É a certeza de que o cotidiano é importante, de que a vida passa onde nos encontramos, aqui e agora ${ }^{3}$.

Se vê o quanto de privilégio em estar com as crianças ${ }^{4}$ repercutiu em cada modo de pensar e moldurar 0 ambiente de uma velha casa ${ }^{5}$, que respeitou de modos simples aos mais importantes a experiência das crianças sentirem, uma a uma, a cada relato e, por fim, uma história, 0 acolhimento não só de espaço, mas de relações e sentimentos.

Enquanto folheamos, percebemos que desse pensar, foi se esquecendo e na realidade cotidiana pouco se nota tanto no professor quanto nos espaços, a importância de se pensar em cada detalhe lembrando das crianças, lembrando que é delas ou seja, mais delas cada cômodo, cada ambiente, o espaço, o lugar: escola. A nós educadores (professores e adultos), vamos pertencendo a este lugar, quando nos pertencemos a infância e a deixamos ser parte em nós.

A competência relacional do professor revela-se, enfim, fundamental para estabelecer relações gratificantes e 'encorajadoras' com as crianças, tendo-se a convicção de que 0 comportamento dos professores é essencial para o desenvolvimento de personalidades equilibradas e, também, para o próprio sucesso das crianças nas atividades escolares [...]. (CATARSI, 2013, p.10).

Para isso é urgente repensar a docência, é preciso estar disponível para com as crianças, suas experiências, seus inícios, estar aberto para pertencer a este lugar, habitado diariamente, não só pelo corpo, mas pelos ouvidos, pelos olhos e pelas ações. Que o espaço se modifique e me modifique ao estar junto das crianças e quando apenas a imaginamos lá.

Organizar: essa seria a palavra de ordem quando pensamos no acolhimento na escola da infância e no envolto de cada dia, poderia ser, mas sequer significaria a ação, pois "[...] antes de mais nada, o resultado da leitura que fazemos do nosso grupo de crianças, a partir, principalmente, de suas necessidades" (BARBOSA, HORN, 2001, p.67).

A escola depósito e cumpridora de favores não pode mais acontecer, se sustentar com esses equívocos. Já que a criança, hoje, vive a maior parte do tempo e de sua vida nesse espaço, iniciando seus primeiros passos, palavras, desenhos, escritas. "[...] A ligação entre o acolhimento e a experiência é, porém, possivvel apenas quando se age com coerência, convicção e método" (STACCIOLI, 2013, p.27).

\footnotetext{
3 Grifo meu.

4 Loide Pereira Trois.

5 Gianfranco Staccioli, 2013, p.2.
} 
Não se pode viver na escola da infância sem reinventar-se todos os dias, acolher com as antenas uma escolha por olhares, estar e sentir o que as crianças nos falam sem as palavras; uma escolha por saberes, buscar escutar o que ainda não ouvimos e ver o quanto aprendemos com as crianças, mesmo sabendo que nós somos quem as "ensinamos".

\begin{abstract}
0 olhar do educador atento é sensível a todos os elementos que estão postos em uma sala de aula. 0 modo como organizamos materiais e móveis, e a forma como crianças e adultos ocupam esse espaço e como interagem com ele são reveladores de uma concepção pedagógica. Aliás, o que sempre chamou minha atenção foi a pobreza frequentemente encontrada nas salas de aula, nos materiais, nas cores, nos aromas; enfim, em tudo que pode povoar o espaço onde cotidianamente as crianças estão e como poderiam desenvolver-se nele e por meio dele se fosse mais bem organizado e mais rico em desafios. (HORN, 2004, p.15).
\end{abstract}

Vejamos todas as referências cuidadosas para estar e se sentir parte deste lugar, no entanto, essa permanência nem sempre se dá desse modo "acolhedor". As crianças, hoje, são recebidas todos os dias pelo aparelho tecnológico chamado televisão, objeto no qual conduz e enfraquece pensamentos, hipnotiza a criatividade e evidencia o poder exercido por adultos. Esse contexto assusta quando evidenciamos um lugar de estar com as crianças, e não apenas de colocar as crianças.

"Os responsáveis pela televisão tratam a infância como um mercado a ser explorado" (RITSCHER 2013, p.18), usando o acervo inventario da infância como dispositivo de propagação e lucrativo. Na continuidade das palavras da autora se destaca o chamamento: "[...] Devemos tentar ouvir, encontrar, acolher, de fato, a infância de modo aberto como se ela mesma fosse uma etnia diferente, digna de todo o nosso interesse e respeito" (2013, p.18-19). Pois é dessa infância que nos constituímos educadores e nos fazemos presentes na vida da criança.

Os espaços de nossa infância nos marcam profundamente. Sejam eles berço, casa, rua, praça, creche, escola, cidade, país, sejam eles bonitos ou feios, confortáveis ou não, 0 fato é que influenciam definitivamente nossa maneira de vermos o mundo e de nos relacionarmos com ele. (CAMARG0, 2008, p.45).

Uma responsabilidade destinada a adultos/educadores, que na maioria das vezes esquece desse atributo e concorda com essas ofertas televisas de substituir as inventivas das crianças por desenhos animados prontos e hipnotizantes. Na obra, 0 autor define 0 adulto como "[...] um expositor cultural em todos os momentos em que tece um diálogo com as crianças - quando propõe, quando oferece experiências, quando corrige, quando mostra os seus interesses [...]" (STACCIOLI, 2013, p. 37).

As palavras delineadas ao professor, que deve ser provocador de aprendizagens, auxiliador de crescimento e acolhedor de culturas, se contradizem ou apenas não se fazem valer no cotidiano que vamos conhecendo nesse tempo atual, sendo retratados através das paredes da escola, na sua organização, nos olhares e na sua voz todo tipo de desenhos condicionantes, esquecendo da infância que chega a este lugar todos dias, com mãos, voz, olhares e gestos. Seres que respiram e que vivem.

É um acolher com mãos e braços, com ações repletas de pensamentos em estar com as crianças, de movimentá-las e retrucá-las ao novo, ao inédito, aos créditos em aprender com elas, pois, "com certeza, a liberdade e a poesia a gente aprende com as crianças" (BARROS, 2013, p.453). E mais, serem professores "[...] que acolhem a experiência porque sabem ler a sua riqueza" (STACCIOLI, 2013, p.27).

Em pensamentos há de passar a ideia de não ser um movimento simples 0 acolhimento, já que requer do adulto um pensamento a altura da criança, e não a criança abaixo do adulto. Em palavras curvadas de disponibilidade, sensível e provocadoras "Um método que acolhe faz apelo à competência do adulto (é muito mais difícil propor situações do que organizar uma intervenção direta)" (STACCIOLI, 2013, p.27). Uma confiança em conjunto, tanto do educador em propor um lugar para a criança, quanto da criança gostar de estar nesse lugar, dando pistas de seu envolvimento.

6 Capitulo que contempla a obra, escrito por Penny Ritscher.

7 Grifo do autor. 
[...] Uma confiança que não é abandono, autonomia equivocada da criança ou, ainda, desinteresse e negligencia. Tornar concreto e cotidiano o princípio de que a criança 'é sujeito de direitos' e que tem direito ao respeito e ao reconhecimento das suas exigências (explicitas e implícitas) é, também, uma tarefa nada fácil. E não é fácil não apenas por causa das condições difíceis que, às vezes, caracterizam certos grupos ou certas situações escolares (por causa do número de crianças ou da presença de poucos professores), mas também porque o respeito é uma escolha que deve se estender ao contexto (a família, 0 ambiente) no qual a criança vive. (STACCIOLI, 2013, p.27).

Uma escolha por afazeres, um trabalho de exigências e arteiro, que na maioria das vezes torna os dias cansativos, memória sugada, criatividade preguiçosa, mas que no final resulta em risos e sorrisos, ou até mesmo um toque de mãos ofegantes querendo pegar no seu cabelo ou tocar seu rosto para dizer que está ali junto de você e com você, "Acolher uma criança é, também, acolher o mundo interno da criança, as suas expectativas, os seus planos, as suas hipóteses e as suas ilusões [...]" (STACCIOLI, 2013, p. 28). Essa ação educativa se dá quando escolhas estar com as crianças, é um privilégio de plenitudes por sentimentos e atrevimentos, de identificação e codificação.

E quando este trabalho, apesar de árduo, se faz valer na vida cotidiana, podemos dizer que "O princípio geral no qual este trabalho se inspira é a confiança" (STACCIOLI, 2013, p. 40). De ser educador aberto ao toque, a luz e a sensibilidade da infância, de organizar e convidar a estar juntos, num mesmo lugar: crianças, adultos e espaço, onde se tenha troca de saberes e respeito, uma pluralidade de cultura. E assim, coloco mais uma vez na voz do autor,

[...] A vida cotidiana nunca é repetitiva. É feita de segmentações, ritmos, repetições, mas são como as ondas do mar, pois se quebram sempre de maneira diferente. E assim são as ações de comer, dormir e ir ao banheiro, uma vez que renovam seus rituais de forma sempre parecida e de maneira sempre diferente. (STACCIOLI, 2013, p.43).

É desse cotidiano que a arte de criar é feita, que a escola da infância é construída e pensada. Uma maneira de juntar ideias boas, não tão boas e que precisavam melhorar, formatando um lugar para conviver e viver, de sentidos, de aromas, de palavras, de relatos, de pessoas pequenas e pessoas grandes, e de pessoas que um dia foram pequenas e que ainda não deixaram de ser, pois buscam conversar a língua das crianças, "Talvez o princípio do acolhimento seja fácil de enunciar e difícil de colocar em prática. Mas é um princípio que oferece, também, satisfação, interesse e um renovado prazer de construir a escola com crianças reais, em meio a pessoas de verdade" (STACCIOLI, 2013, p.45).

\section{Considerações finais}

Elas estão chegando! Sim, todos os dias chegam à escola com suas famílias ou com seus pares e trazem nas "mochilas" suas histórias, suas culturas e experiências, desejando serem ouvidas, participarem e transformarem a escola num lugar de vida, de cores, sabores, invenções e brincadeiras.

Como últimas palavras reiteramos que acolher é possível, imprescindível, urgente e necessário, e que cabe a cada um de nós inspirarmo-nos nesta experiência italiana, ousar e atrever-se a construir novos e diferentes jeitos brasileiros de acolher em cada escola infantil, transformando as configurações dos espaços e do tempo através de seus barulhos e/ou silêncios.

Precisamos ser tocados pelas pistas cotidianas que as crianças nos apresentam através de suas múltiplas linguagens, e com isso nos comprometermos com elas a ponto de revirar as nossas intenções carregadas de homogeneidades a espera de resultados em tempos iguais, abrir mão desta posse de controlar a tudo e a todos, deixando de lado os autores principais que são as crianças. E para isso tornar-se consciente é necessário um trabalho de parceria entre educadores e gestores que se comprometam com as importâncias (BARROS, 2003) da escola infantil, com o que faz sentido para a vida das crianças neste espaço coletivo chamado escola.

Deseja-se que sejamos tocados pelas bocas lambuzadas de sabores, pelas mãozinhas que nos pedem mudanças, que possamos acolher com ouvidos, olhos e sentimentos, que a televisão não faça mais o nosso trabalho de encantar e querer estar, enfim, que se tenha vontade de estar, por inteiro, com as crianças, fazendo às partes do cotidiano, e não estando à parte no cotidiano. 
E quando todo esse desejo transborda, precisamos nos perguntar: que escola da infância é esta que promove desde muito cedo na vida de cada sujeito a pedagogia da mesmice, da folhinha, do filme, da reprodução e do silenciamento? Que nega os barulhos, as melecas, as cores, as marcas e os rastros que as crianças deixam por onde passam?

Muitos autores nos ajudam a problematizar este contexto e a vislumbrar possíveis percursos mais inventivos, humanos, brincantes, reinventando este lugar que diariamente chegam as crianças, que passam as crianças e se passa com as crianças.

0 princípio de tudo é compreendermos que este é o jeito de se fazer escola e de ser educador da infância, aquele que se transborda com as coisas desimportantes (BARROS, 2003) e que as torna as mais complexas e intensas obras cotidianas. Que recria possibilidades, que embarca em múltiplas viagens do mundo do faz de conta com as crianças e que cria contextos instigadores dos acontecimentos da vida cotidiana.

\section{Referências}

BARBOSA, M. C. S.; HORN, M. G. S. Organização do espaço e do tempo na escola infantil. In: CRAIDY, C.; KAERCHER, G. E. Educação Infantil. Pra que te quero? Porto Alegre: Artmed, 2001.

BARROS, M. Memórias inventadas: a infância. São Paulo: Planeta, 2003.

BARROS, M. Poesia completa. São Paulo: Leya, 2013.

CAMARGO, P. Desencontros entre Arquitetura e Pedagogia. Revista Pátio Educação Infantil, Porto Alegre, ano VI, n. 18, p. 44-47, nov. 2008.

FOCHI, P. S. "Mas os bebês fazem o quê no berçário, heim?": documentando ações de comunicação, autonomia e saber-fazer de crianças de 6 a 14 meses em contextos de vida coletiva. 2013. 172 f. Dissertação (Mestrado) Programa de Pós Graduação em Educação, Universidades Federal do Rio Grande do Sul (UFRGS), Porto Alegre, 2013.

FOCHI, P,; BARBOSA, M. C. S. 0 desafio da pesquisa com bebês e crianças bem pequena IX ANPEDSUL (Seminário de Pesquisa em Educação da Região Sul), 2013.

FORTUNATI, A. A educação infantil como projeto da comunidade. Tradução Ernani Rosa. Porto Alegre: Artmed, 2009.

HORN, M. G. S. Sabores, cores, sons, aromas: A organização dos espaços na Educação Infantil. Porto Alegre: Artmed, 2004.

SARMENTO, M. J. "Estamos longe de garantir o direito à participação das crianças". (Entrevista). De olho no Plano, 2011. Disponível em: http://www.deolhonoplano.org.br/not0036.html.

STACCIOLI, G. Diário do acolhimento na escola da infância. Campinas (SP): Autores Associados, 2013. 